Check for updates

Cite this: Chem. Sci., 2018, 9, 8860

๑ All publication charges for this article have been paid for by the Royal Society of Chemistry

Received 25th July 2018

Accepted 18th September 2018

DOI: $10.1039 / c 8 s c 03297 a$

rsc.li/chemical-science

\section{Ultrathin Fe-NiO nanosheets as catalytic charge reservoirs for a planar Mo-doped $\mathrm{BiVO}_{4}$ photoanode $\uparrow$}

\author{
Lei Li, ${ }^{\text {ab }}$ Xiaogang Yang, (D) *abc Yan Lei, (D) ${ }^{\text {ac }}$ Haili Yu, ad Zhongzheng Yang, ${ }^{\text {ab }}$ \\ Zhi Zheng ${ }^{\star a c}$ and Dunwei Wang ${ }^{\mathrm{e}}$
}

The energy conversion efficiency of a photoelectrochemical system is intimately connected to a number of processes, including light absorption, charge excitation, separation and transfer processes. Of these processes, the charge transfer rate at the electrodelelectrolyte interface is the slowest and, hence, the rate-limiting step causing charge accumulation. Such an understanding underpins efforts focused on applying highly active electrocatalysts, which may contribute to the overall performance by augmenting surface charge accumulation, prolonging charge lifetime or facilitating charge transfer. How the overall effect depends on these individual possible mechanisms has been difficult to study previously. Aiming at advancing knowledge about this important interface, we applied first-order serial reactions to elucidate the charge excitation, separation and recombination kinetics on the semiconductorlelectrocatalyst interfaces in air. The study platform for the present work was prepared using a two-step Mo-doped $\mathrm{BiVO}_{4}$ film modified with an ultrathin Fe-doped $\mathrm{NiO}$ nanosheet, which was derived from an Fe-doped $\alpha$ $\mathrm{Ni}(\mathrm{OH})_{2}$ nanosheet by a convenient precipitation and ion-exchange method. The simulation results of the transient surface photovoltage (TSPV) data showed that the surface charge accumulation was significantly enhanced, even at an extremely low coverage $(0.12-120$ ppm) using ultra-thin Fe-NiO nanosheets. Interestingly, no improvement in the charge separation rate constants or reduction of recombination rate constants was observed under our experimental conditions. Instead, the ultra-thin $\mathrm{Fe}-\mathrm{NiO}$ nanosheets served as a charge storage layer to facilitate the catalytic process for enhanced performance.

\section{Introduction}

The photoelectrochemical (PEC) reaction is one of the most promising methods for solar energy conversion and storage and, therefore, has attracted tremendous research attention., ${ }^{1,2}$ The key components include a semiconducting photo-absorber, and a co-catalyst to accelerate the surface redox reactions in the electrolyte. ${ }^{3}$ Due to the complicated requirements of the high

${ }^{a}$ Key Laboratory for Micro-Nano Energy Storage and Conversion Materials of Henan
Province, College of Advanced Materials and Energy, Institute of Surface Micro and
Nanomaterials, Xuchang University, Xuchang, Henan 461000, China. E-mail:
xiaogang.yang@gmail.com; zzheng@xcu.edu.cn
${ }^{b}$ Henan Key Material Laboratory, North China University of Water Resources and
Electric Power, Zhengzhou, Henan, 450045, China
${ }^{c}$ Henan Joint International Research Laboratory of Nanomaterials for Energy and
Catalysis, Xuchang University, Xuchang, Henan 461000, China
${ }^{d}$ College of Chemistry and Molecular Engineering, Zhengzhou University, Zhengzhou,
Henan, 450001, China
${ }^{e}$ Department ofChemistry, Merkert Chemistry Center, Boston College, 2609 Beacon St.,
Chestnut Hill, MA 02467, USA $\uparrow$ Electronic supplementary information (ESI) available. See DOI: $10.1039 / \mathrm{c} 8 \mathrm{sc} 03297 \mathrm{a}$ efficient light absorption/excitation, separation and transfer kinetics, the heterogeneous materials possess great advantages over single-component ones. ${ }^{4-6}$ For example, the co-catalyst on the semiconductors can display various effects on the charge reaction rates. ${ }^{-9}$ Given the extremely sluggish surface redox reaction rate (ms-s) and the short charge lifetime (ps- $\mu \mathrm{s}),{ }^{10}$ how to manipulate the heteronanostructure or the interface between the semiconductor and the catalyst becomes critical for the high-efficiency charge separation/transfer rate., ${ }^{6,11}$

Take $\mathrm{BiVO}_{4}\left(E_{\mathrm{g}}=2.4 \mathrm{eV}\right)$ as an example. It is an earth abundant n-type semiconductor that has been widely applied as a photoanode for water splitting ${ }^{12-14}$ or $\mathrm{CO}_{2}$ reduction. ${ }^{15,16}$ Generally, it suffers from slow charge separation/transport, slow electron mobility, ${ }^{17}$ and poor water oxidation kinetics. ${ }^{18}$ Various strategies have been proposed to address these issues, ${ }^{19}$ such as (1) increasing the doping density by introducing Mo or $\mathrm{W}$ dopants, ${ }^{20,21}$ or oxygen vacancies by hydrogen treatments; ${ }^{22}$ (2) incorporating an $\mathrm{SnO}_{2}$ underlayer to reduce interface charge recombination $;^{23}$ (3) fabricating heterojunctions for larger builtin electric fields; $;^{24,25}(4)$ enlarging surface band bending by long time photocharging ${ }^{26,27}$ or electrochemical treatments; ${ }^{28}$ and (5) employing oxygen evolution catalysts (OECs) to lower the 
activation energy $\left(E_{\mathrm{a}}\right)$ and increase the charge transfer rate. For $\mathrm{BiVO}_{4} / \mathrm{OEC}$ heteronanostructures, crystalline $\mathrm{NiOOH} / \mathrm{FeOOH}$, $\mathrm{Ni}(\mathrm{OH})_{2}, \mathrm{NiO}, \mathrm{CoO}, \mathrm{Co}_{3} \mathrm{O}_{4}$, amorphous Co-Pi and $\mathrm{NiFeO}_{x}$ have been successfully used, showing significant PEC performance enhancements. At least four possible functions of the OECs have been proposed. First, a typical catalyst can increase the charge separation/transfer, resulting in the decrease of surface recombination. ${ }^{\mathbf{1 3} 29}$ For example, by coating $\mathrm{BiVO}_{4}$ with a $\mathrm{FeOOH}$ layer, researchers obtained a substantially increased hole collection at the solid|liquid junction, which is responsible for the high measured photocurrents. ${ }^{\mathbf{1 8 , 3 0}}$ For another example, an ultrathin $\mathrm{CoO}_{x}(1 \mathrm{~nm})$ catalyst layer allowed greater hole collection as opposed to faster kinetics. ${ }^{31}$ By comparison, amorphous cobalt phosphate (Co-Pi: $30 \mathrm{~nm}$ ) increased the charge transfer kinetics. ${ }^{32}$ Second, the suppression of surface recombination led to a high photovoltage (band bending), causing faster surface reactions with higher photocurrent. ${ }^{33}$ To this end, the Durrant group employed transient absorption spectroscopy (TAS) to demonstrate the retardation of electron/ hole recombination. ${ }^{34}$ They did not observe any evidence of catalytic behaviours. When studying the $\mathrm{CoPi}, \mathrm{FeOOH}$ or $\mathrm{NiFeO}_{x}$ catalysts on $\mathrm{BiVO}_{4}$ with the intensity modulated photocurrent spectroscopy (IMPS), ${ }^{35}$ the photocurrent was found to be limited by fast surface recombination rate rather than surface catalysis. Third, charge separation/transfer can be intrinsically increased by the built-in electronic field in heterojunctions (e.g., p-n junction). ${ }^{36,37}$ Chang et al. introduced discrete p-type $\mathrm{Co}_{3} \mathrm{O}_{4}$ co-catalysts on $\mathrm{BiVO}_{4}$ to form a p-n heterojunction, which was shown to facilitate charge separation, increasing surface reactions and suppressing recombination at the interface. ${ }^{38}$ Similarly, a Ni-doped $\mathrm{CoO}_{x}$ uniform layer (ptype) increased the surface band bending with a cathodic $V_{\text {on }}$ shift and photocurrent increase. ${ }^{39}$ This surface band bending enhancement also resulted in the reduction of surface charge recombination on the $\mathrm{NiO} / \mathrm{CoO}_{x} / \mathrm{BiVO}_{4}$ photoanode. ${ }^{37}$ In addition, the hole-storage layer effect of ferrihydrite was suggested on $\mathrm{BiVO}_{4}$ and $\mathrm{Ta}_{3} \mathrm{~N}_{5}$ photoanodes. ${ }^{\mathbf{4 0 , 4 1}}$ Despite these advances, it has been difficult to fully understand what the true causes are for the observed performance improvements at the semiconductor|electrocatalyst interface. Therefore, charge behaviours at the semiconductor|electrocatalyst interface remain relatively poorly understood, presenting a challenge for further improvement of PEC systems. This interface is thus of great importance and has attracted significant research attention.

To discern the thermodynamic and kinetic influences at this interface, the Boettcher group has successfully employed a dualworking-electrode (DWE) method to scrutinize the photovoltage and charge transfer differences between the adaptive and dense semiconductor|catalyst junctions in the electrolyte. ${ }^{\mathbf{4 2 4 3}}$ Their secondary working electrodes could be used to either probe or control the catalyst/electrolyte interface in situ, so that the electrochemical potential/current of the catalyst can be independently measured. ${ }^{9}$ Separately, the Durrant group has measured a $3^{\text {rd }}$ order oxygen evolution reaction (OER) order with regard to surface hole concentrations on $\mathrm{BiVO}_{4}$ under higher surface hole densities $\left(>1 \mathrm{~nm}^{-2}\right)$ based on photoinduced absorption analysis (PIA). ${ }^{44} \mathrm{~A} 1^{\text {st }}$ order OER rate dependence on the hole concentration was found when the surface hole density was low $\left(<1 \mathrm{~nm}^{-2}\right)$. Results like these raise important questions concerning the detailed processes and their influence on the overall performance of photoelectrodes in PEC reactions. For instance, at low surface coverage, does a co-catalyst influence the system by changing the kinetics or surface energetics? How does the charge accumulated at the semiconductor|electrocatalyst interface contribute to the photoelectrochemical reactions? Similar questions were difficult to answer using existing methodologies. To correct this deficiency, here we report a simple transient surface photovoltage (TSPV) analysis ${ }^{\mathbf{4 5 - 4 7}}$ that can directly monitor the accumulated charges at the semiconductor|air or semiconductor|electrocatalyst interface, especially under the open-circuit condition. We show that the technique is an important tool to advance our understanding of the interface charge phenomena. The merit of this TSPV method is the ability to individually study charge separation/transfer at the semiconductor|electrocatalyst interface with negligible redox reactions because the system is an open circuit.

For this body of research, we chose crystalline ultrathin Fedoped $\mathrm{NiO}_{x}(\mathrm{Fe}-\mathrm{NiO})$ nanosheets as an oxygen evolution catalyst on planar Mo-doped $\mathrm{BiVO}_{4}\left(\mathrm{Mo}-\mathrm{BiVO}_{4}\right)$ films. The system was first studied in air before in a contacting electrolyte, as our goal was to elucidate the charge separation kinetics. Different from the previously reported synthesis method of $\mathrm{Ni}(\mathrm{OH})_{2}$ catalyst by plasma deposition $^{48}$ or in situ electrochemical decomposition, ${ }^{\mathbf{1 3 , 1 4 , 3 0}}$ we simply prepared ultrathin Fe-doped $\mathrm{Ni}(\mathrm{OH})_{2}$ nanosheets through a precipitation and ion-exchange method. The catalyst was spin-coated onto the $\mathrm{Mo}^{-\mathrm{BiVO}_{4}}$ films and thermally converted to a discrete ultrathin Fe-NiO catalyst layer. Next, we applied the TSPV to investigate the surface charge accumulation kinetics on the semiconductor|electrocatalyst interface in air. Simulation of the kinetics was carried out, and we observed an apparent first-order dependence of charge separation and recombination on charge concentrations. An increased surface charge accumulation was observed at the Mo$\mathrm{BiVO}_{4} / \mathrm{Fe}-\mathrm{NiO}$ interface, implying that the catalyst serves as a charge "reservoir", despite its relatively low loading. The Fe$\mathrm{NiO}$ modified $\mathrm{Mo}^{-\mathrm{BiVO}_{4}}$ photoanode showed a significant overall enhancement for water oxidation in an alkaline electrolyte $(1 \mathrm{M} \mathrm{NaOH})$ with high charge transfer efficiencies. The charge separation and transfer efficiencies at the semiconductor|electrolyte interface were also investigated during the PEC test with and without Fe-doped NiO catalyst, respectively.

\section{Experimental sections}

\section{Materials}

FTO substrate was purchased from Huanan Xiangcheng Sci. Co. (Shenzhen); the Bi target was obtained from Zhongcheng New Materials Co. (Beijing). The chemical reagents such as vanadyl acetylacetonate $\left(\mathrm{VO}(\mathrm{acac})_{2}\right)$, molybdenyl acetylacetonate $\left(\mathrm{MoO}_{2}(\mathrm{acac})_{2}\right), \mathrm{NaOH}, \mathrm{Ni}\left(\mathrm{NO}_{3}\right)_{2} \cdot 6 \mathrm{H}_{2} \mathrm{O}, \mathrm{Fe}\left(\mathrm{NO}_{3}\right)_{3} \cdot 9 \mathrm{H}_{2} \mathrm{O}$, and dimethyl sulfoxide (DMSO) are commercially available from Sinopharm Chemical reagent (Shanghai), Sigma-Aldrich and Alfa Aesar Chem. 


\section{Preparation of Mo-doped $\mathrm{BiVO}_{4}$ film}

FTO glass was ultrasonically cleaned in $\mathrm{a}_{2} \mathrm{O} / \mathrm{H}_{2} \mathrm{O}_{2} / \mathrm{NH}_{3} \cdot \mathrm{H}_{2} \mathrm{O}$ $(1 / 1 / 1 \mathrm{v} / \mathrm{v} / \mathrm{v})$ solution, washed with deionized (DI) water and naturally dried in air. Next, a Bi metal film (40 nm) was vacuum deposited on a FTO substrate with a K575XD Ar ion sputter. Following the previously reported methods, ${ }^{13}$ Mo-doped $\mathrm{BiVO}_{4}$ films were prepared by a two-step process. Briefly, $30 \mu \mathrm{L}$ of $\mathrm{VO}(\mathrm{acac})_{2}$ in DMSO $(0.5 \mathrm{M})$ was cast coated on the Bi film $(1 \mathrm{~cm} \times 2 \mathrm{~cm})$ and dried in an oven, before being slowly heated in a muffle furnace to $450{ }^{\circ} \mathrm{C}$ (heating rate at $2{ }^{\circ} \mathrm{C}$ per minute) and maintained at $450{ }^{\circ} \mathrm{C}$ for $4 \mathrm{~h}$. The resulting brownish films were soaked in $1 \mathrm{M} \mathrm{NaOH}$ solution for 20-30 min, rinsed with DI water to remove excess vanadate impurities, followed by post annealing at $500{ }^{\circ} \mathrm{C}$ for $2 \mathrm{~h}$. The obtained films were denoted as undoped $\mathrm{BiVO}_{4}$. In the second step, a mixed solution containing $\mathrm{MoO}_{2}(\mathrm{acac})_{2}$ and $\mathrm{VO}(\mathrm{acac})_{2}$ in a DMSO solution $(\mathrm{Mo} / \mathrm{V}=5 \%$ in molar ratio) was cast on the $\mathrm{BiVO}_{4}$ films, slowly heated to $450{ }^{\circ} \mathrm{C}$ and sequentially treated at $500{ }^{\circ} \mathrm{C}$ for $2 \mathrm{~h}$. After the impurities were removed using $\mathrm{NaOH}$ and DI water, the obtained film was denoted as two-step Mo-doped $\mathrm{BiVO}_{4}$ (2-Mo-BiVO ${ }_{4}$ ). Single conversion process was used for homogenous 1-Mo-BiVO ${ }_{4}$ with the same mixed $\mathrm{Mo} / \mathrm{V}$ precursor solution.

\section{Synthesis of ultrathin Fe-doped NiO nanosheets on 2-Mo- $\mathrm{BiVO}_{4}$}

$25 \mathrm{~mL}$ of $\mathrm{Ni}\left(\mathrm{NO}_{3}\right)_{2}$ solution $(0.1 \mathrm{M})$ was added into $1 \mathrm{M} \mathrm{NaOH}$ solution $(6 \mathrm{~mL})$ dropwise under vigorous stirring for $10 \mathrm{~min}$. The resulting light greenish $\mathrm{Ni}(\mathrm{OH})_{2}$ precipitate was centrifugated and washed using DI water several times, which was re-dispersed in $20 \mathrm{~mL}$ DI water. $300 \mu \mathrm{L}$ of $\mathrm{Fe}\left(\mathrm{NO}_{3}\right)_{3}(1 \mathrm{M})$ was added to the above $\mathrm{Ni}(\mathrm{OH})_{2}$ dispersion, allowing ion exchange under ultrasonic treatment for $2 \mathrm{~h}$. The resulting brownish dispersion was centrifugated/washed in DI water several times to remove the excess ions. In the end, the obtained precipitation was denoted as Fe-doped $\mathrm{Ni}(\mathrm{OH})_{2}$. It was re-dispersed in DI water $\left(120 \mu \mathrm{g} \mathrm{mL}^{-1}\right.$ or $\left.120 \mathrm{ppm}\right)$, which was spin-coated onto 2-

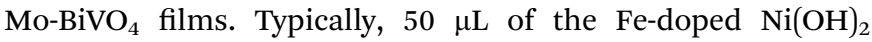
dispersion was spread on a $2-\mathrm{Mo}^{-} \mathrm{BiVO}_{4}$ film spinning at 3000 $\mathrm{rpm}$ for $60 \mathrm{~s}$. After thermal annealing at $300{ }^{\circ} \mathrm{C}$ for $2 \mathrm{~h}$ in air, the 2-Mo-BiVO $4 / \mathrm{Fe}-\mathrm{NiO}-120$ film was obtained. For the other loading amounts, the dispersion for spin-coating was diluted to $12 \mathrm{ppm}, 1.2 \mathrm{ppm}$ and $0.12 \mathrm{ppm}$, respectively.

\section{Structure, optical and photoelectronic characterization}

$\mathrm{X}$-ray powder diffraction (XRD) was conducted on a Bruker X-ray diffractometer (D8 Advance, $\mathrm{Cu} \mathrm{K}_{\alpha}, \lambda=1.5418 \AA$ ) in the range of $10^{\circ}-70^{\circ}$. Scanning electron microscopy (SEM) was observed on a field emission scanning electron microscope (FEI, Nova NanoSEM450). High resolution TEM image and electron diffraction were obtained on a transmission electron microscope (FEI Tecnai G2 F20) under $200 \mathrm{kV}$. The thickness/height image, photoconductive topology and Kelvin probe force microscopy were collected on a conductive atomic force microscope (C-AFM, Bruker Dimension Icon, coupled with AM 1.5G light) under ambient conditions, using conductive AFM probes (Bruker, PFTUNA and SCM-PIT, respectively). The Fedoped $\mathrm{NiO}$ samples $\left(>80 \mathrm{~cm}^{2}\right)$ were dissolved into dilute $\mathrm{HNO}_{3}$; after that, the surface catalyst loading amount was checked by inductive coupled plasma mass spectroscopy (ICP-MS, Agilent 7700). The XPS data were collected on a spectrometer (Thermo Scientific Escalab 250Xi), and Raman spectra were collected on a Renishaw confocal Raman microscope (in Via Reflex) using a green laser $(532 \mathrm{~nm})$ in the range of $200-1000 \mathrm{~cm}^{-1}$. The optical properties of the produced films were measured in the transmission mode with a UV-vis spectrophotometer (Agilent Tech. Cary 5000). The transient surface photovoltage was investigated on a home-made capacitor-like spectroscope, ${ }^{\mathbf{4 6 , 4 9}}$ where a Quantel Nd:YAG nanosecond laser (Brilliant Eazy, BRILEZ/IR) was used as the excitation source (355 nm, $4 \mathrm{~ns}$, spot area of $0.24 \mathrm{~cm}^{2}$ ), coupled with a digital oscilloscope (Tektronix, TDS 3054C, $500 \mathrm{MHz}$ ) and pre-amplifier for recording. A sandwich structure of FTO|mica|BiVO a metal faradaic container, where a mica $(\sim 70 \mu \mathrm{m})$ was used as spacer.

\section{Photoelectrochemical and impedance measurements}

The photoelectrode was prepared by connecting a $\mathrm{Cu}$ wire with silver adhesive to a FTO substrate, encapsulated with insulated cross-linked rubber only with the active area exposed. The PEC measurements were carried out using a three-electrode configuration on a potentiostat (CHI 660E, Shanghai), with a counter electrode ( $\mathrm{Pt}$ wire) and a reference electrode $(\mathrm{Hg} / \mathrm{HgO}$, in $1 \mathrm{M}$ $\mathrm{NaOH}, 0.098 \mathrm{~V} v s$. NHE) in an electrolyte solution (1 M NaOH, $\mathrm{pH}=13.5)$. The potential was converted to the reversible hydrogen electrode (RHE) scale following this equation: $E=E_{\mathrm{Hg}}$ / $\mathrm{HgO}+0.098+0.059 \times 13.5$. A standard simulated solar illuminator (AM 1.5G on Newport 94023, $100 \mathrm{~mW} \mathrm{~cm}^{-2}$ ) was chosen as the light source. The polarization $J-V$ curves were recorded using a linear sweep technique with a scanning rate of $20 \mathrm{mV} \mathrm{s}^{-1}$ in the range of $0.2-1.6 \mathrm{~V}$ ( $v s$. RHE) with backside illumination. The

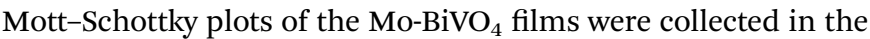
dark in $1 \mathrm{M} \mathrm{NaOH}$ (containing $2 \mathrm{mM} \mathrm{Fe}(\mathrm{CN})_{6}{ }^{3-} / \mathrm{Fe}(\mathrm{CN})_{6}{ }^{4-}$ ) to determine the flat band position. The electrochemical impedance spectroscopy (EIS) of the electrodes was measured at $1.5 \mathrm{~V}$ vs. RHE from $10^{5}$ to $0.1 \mathrm{~Hz}$ with an AC amplitude of $5 \mathrm{mV}$ in a $1 \mathrm{M} \mathrm{NaOH}$ electrolyte. The cyclic voltammetry (CV) curves were analysed in the same electrolyte from 1.1 to $1.6 \mathrm{~V} v s$. RHE.

\section{Results and discussion}

To investigate the charge separation at the $\mathrm{Mo}^{-\mathrm{BiVO}_{4}} / \mathrm{Fe}-\mathrm{NiO}$ interface, we start to prepare the Fe-doped NiO catalyst and Mo$\mathrm{BiVO}_{4}$ semiconductor separately before integrating them together. For the synthesis of the Fe-NiO catalyst, $\mathrm{Ni}(\mathrm{OH})_{2}$ was freshly precipitated from a solution, which was converted to Fedoped nickel hydroxide under ultrasonic agitation. In Fig. 1(a), this layered structure can be well confirmed by the XRD pattern $\left(\alpha-\mathrm{Ni}(\mathrm{OH})_{2} \cdot 0.75 \mathrm{H}_{2} \mathrm{O}\right.$, JCPDS card, no. 38-0715) in the bottom (black curve), where only (003) and (006) diffraction peaks were shown. Then, the ultrathin Fe-doped NiO nanosheet was obtained through a thermal conversion of the layered hydroxides 

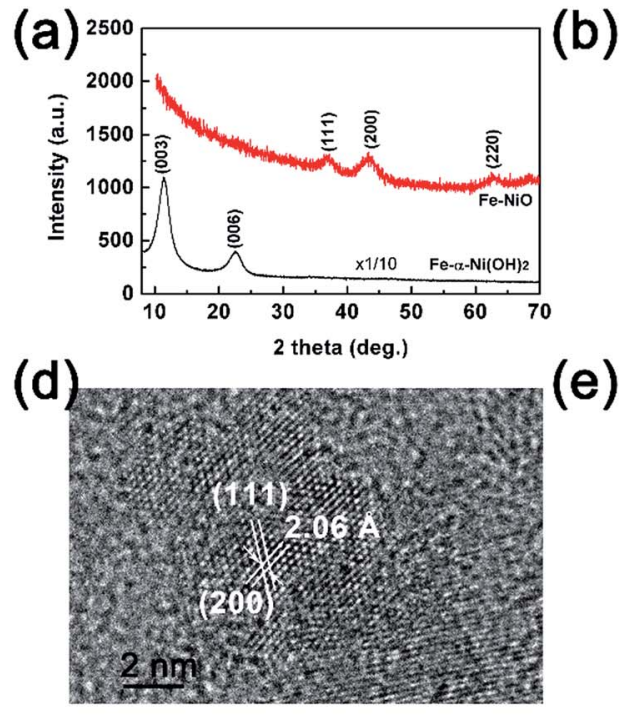

(b)
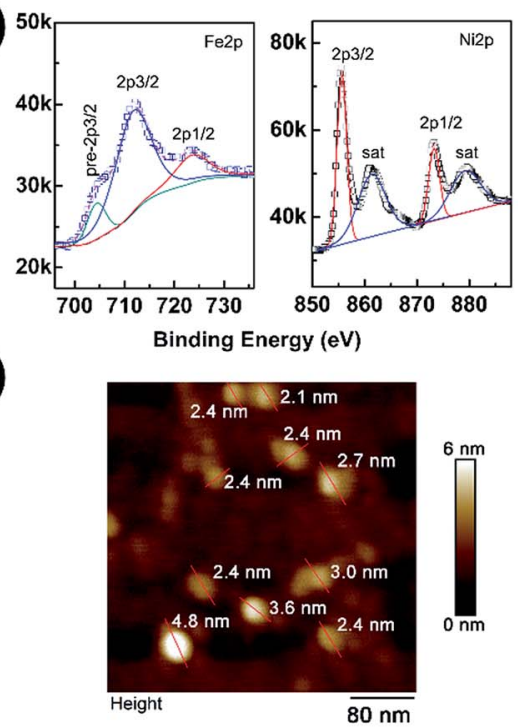

(c)

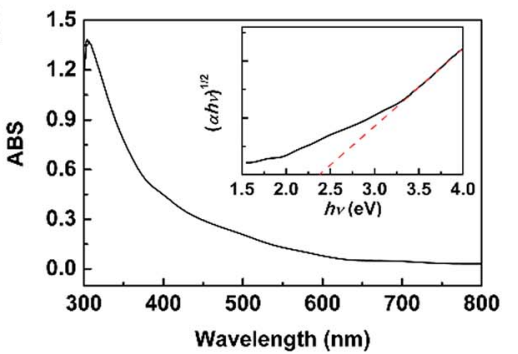

(f)

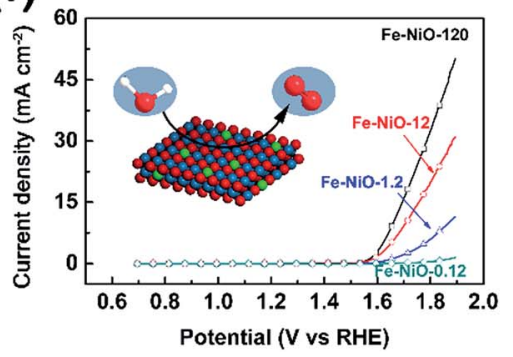

Fig. 1 (a) XRD patterns of the Fe-doped $\mathrm{Ni}(\mathrm{OH})_{2}$ precipitate (black curve at bottom) and Fe-doped $\mathrm{NiO}$ (red curve on the top); (b) XPS spectra of the Fe-NiO film (left: Fe2p; right: Ni2p); (c) UV-vis absorption spectrum of the Fe-NiO film, the inset was the Tauc plot of indirect band estimation; (d) HR-TEM image of the Fe-NiO nanosheet; (e) AFM height image of the Fe-NiO nanosheets; (f) J-V curves of the Fe-NiO nanosheets on FTO prepared with various concentrations in a $1 \mathrm{M} \mathrm{NaOH}$ electrolyte, and a scanning rate of $20 \mathrm{mV} \mathrm{s}^{-1}$.

at $300{ }^{\circ} \mathrm{C}$. In Fig. 1(a), the red curve displays three peaks at $37.05^{\circ}, 43.31^{\circ}$ and $62.83^{\circ}$, corresponding to a slightly contracted lattice constant of $a=4.185 \AA$ of a face-centred cubic NiO structure (JCPDS card, no. 65-2901) and close to the NiO nanosheets ( $a=4.182 \AA$, with $\sim 0.1 \%$ lattice strain) prepared by similar processes (XRD pattern in Fig. S1 $\dagger$ ). This lattice increment of $\mathrm{NiO}$ after Fe doping agreed well with a previous report. ${ }^{50}$ In Fig. 1(b), the binding energies of Fe2p and Ni2p electrons are shown, respectively. The Fe2p peak can be deconvoluted as $\mathrm{Fe} 2 \mathrm{p}_{3 / 2}, \mathrm{Fe} 2 \mathrm{p}_{1 / 2}$ and a pre-2 $\mathrm{p}_{3 / 2}$ peak at $711.7 \mathrm{eV}, 723.5 \mathrm{eV}$ and $704.4 \mathrm{eV}$, respectively. This is in good agreement with a $\mathrm{Fe}^{3+}$ state. ${ }^{50}$ For the Ni2p peaks, two sets of Ni2 $p_{3 / 2}, N_{2} 2 p_{1 / 2}$ and their satellite peaks were shown at $855.6 \mathrm{eV}, 873.2 \mathrm{eV}$ and $861.3 \mathrm{eV}$ and $879.2 \mathrm{eV}$, respectively, corresponding to a $\mathrm{Ni}^{2+}$ in the $\mathrm{Fe}-$ doped NiO product. ${ }^{50}$ XPS showed that the element molar ratio of $\mathrm{Fe} / \mathrm{Ni}$ was $\mathrm{ca} .27 \% / 73 \%$. The higher Fe doping level may be due to the comparable radius of $\mathrm{Fe}^{3+}(64.5 \mathrm{pm})$ and $\mathrm{Ni}^{2+}(69 \mathrm{pm})$ with a six-fold coordination, ${ }^{51}$ and/or large surface/volume ratio to release the lattice stress (strain).

Thus, the preparation process can be demonstrated through three steps: $\alpha-\mathrm{Ni}(\mathrm{OH})_{2}$ precipitation as in eqn (1), $\mathrm{Fe}^{3+}$ ion exchange in the precipitation as in eqn (2), and thermal dehydration to $\mathrm{Fe}(3+)$-doped $\mathrm{NiO}$ in eqn (3):

$$
\begin{gathered}
\mathrm{Ni}^{2+}+2 \mathrm{OH}^{-} \rightarrow \mathrm{Ni}(\mathrm{OH})_{2} \\
x \mathrm{Fe}^{3+}+\mathrm{Ni}(\mathrm{OH})_{2}+x \mathrm{H}_{2} \mathrm{O} \rightarrow \mathrm{Fe}_{x} \mathrm{Ni}_{1-x}(\mathrm{OH})_{2+x}+x \mathrm{Ni}^{2+}+x \mathrm{H}^{+}
\end{gathered}
$$$$
\mathrm{Fe}_{x} \mathrm{Ni}_{1-x}(\mathrm{OH})_{2+x} \rightarrow \mathrm{Fe}_{x} \mathrm{Ni}_{1-x} \mathrm{O}_{1+x / 2}+\frac{1+x}{2} \mathrm{H}_{2} \mathrm{O}
$$

For simplicity, we used Fe-NiO to represent the product of $\mathrm{Fe}_{x} \mathrm{Ni}_{1-x} \mathrm{O}_{1+x / 2}$.
The light absorption of the obtained brownish Fe-NiO on FTO was investigated in Fig. 1(c). The sample showed strong absorption between 300 and $550 \mathrm{~nm}$. Using the Tauc plot (inserted in Fig. 1(c)), the indirect light absorption band can be calculated as $2.35 \mathrm{eV}$. Although the general undoped NiO had a wide bandgap $(\sim 3.6 \mathrm{eV}),{ }^{52}$ the introduction of Fe dopants resulted in a narrower bandgap due to the less occupation of dbands of the Fe atoms than the Ni atoms. This observed indirect bandgap coincides with the one calculated by first principles (2.26 eV for $25 \%$ doping). ${ }^{53}$ The high resolution TEM image of the Fe-NiO revealed a highly crystalline structure with the zone axis of [220] in Fig. 1(d), where the lattices separated by $2.06 \AA$ and $2.38 \AA$ were assigned to the (200) and (111) planes, respectively. The angle between these two planes was $c a .54^{\circ}$. Combining the HR-TEM image with the XRD pattern, we expect an ultrathin oriented flake morphology. Then, we prepared a FeNiO sample on a Si wafer from a dilute dispersion (1.2 ppm) for thickness evaluation. In Fig. 1(e), the AFM height image displays a typical 2-dimensional morphology with a width of 25$60 \mathrm{~nm}$ (size distribution shown in Fig. S2†) and a thickness of 2.1-4.8 $\mathrm{nm}$. Given that the distance between the (220) planes is ca. $1.5 \AA$, this thickness corresponds to 14-32 layers of nanosheets. When the ultrathin Fe-NiO nanosheets were deposited on the FTO substrate from various concentrations, they all displayed a highly catalytic activity as shown in Fig. 1(f). The current-potential $J-V$ curves showed a dramatic current increase (e.g., $1 \mathrm{~mA} \mathrm{~cm}{ }^{-2}$ ) when the applied potential was above $1.57 \mathrm{~V}$ (vs. RHE), with the increasing Fe-NiO loading amount. In Fig. S3, $\uparrow$ the EDS mapping images of $\mathrm{Fe}, \mathrm{Ni}$ and $\mathrm{O}$ were displayed, showing a uniform distribution of $\mathrm{Fe}$ and $\mathrm{Ni}$ in the electrocatalyst. Although the exact loading amount of the catalyst on FTO may be not strictly proportional to the content of the solid precursor in the suspension, the electrocatalytic 
performance showed a positive correlation to the precursor content. Compared with the other OER catalysts, such as $\mathrm{NiCoO}_{x}, \mathrm{NiOOH}, \mathrm{Ni}(\mathrm{OH})_{2}, \mathrm{NiFeO}_{x}, \mathrm{NiOOH}, \mathrm{CoOOH}, \mathrm{Co}-\mathrm{Pi}$ or $\mathrm{NiO},{ }^{48,54}$ the overpotential $\left(0.27 \mathrm{~V}\right.$ for $\left.0.1 \mathrm{~mA} \mathrm{~cm}^{-2}\right)$ on ultrathin Fe doped NiO nanosheets is promising for practical OER applications.

The planar Mo-doped bismuth vanadate films were thermally converted from Bi films $(40 \mathrm{~nm})$ on the FTO substrate, using $\mathrm{VO}(\mathrm{acac})_{2}$ as the vanadium source and $\mathrm{MoO}_{2}(\mathrm{acac})_{2}$ as the doping precursor in DMSO as reported in the literatures. ${ }^{13}$ The 2-Mo-BiVO 4 film on the FTO substrate was characterized by Xray powder diffraction using a $\mathrm{Cu}$ target. In Fig. 2(a), the peaks marked with red “*” are all ascribed to the diffractions of (011), (112), (004), (121), (006), (204), (301) and (116) on a monoclinic $\mathrm{BiVO}_{4}$ structure (JCPDS card, no. 83-1699). Based on the XRD pattern, the lattice constants $(a=5.177 \AA$ А $b=5.123 \AA$, $c=11.71$ $\AA$ and $\gamma=90.20^{\circ}$ ) were obtained, which were close to bare and one-step Mo-doped $\mathrm{BiVO}_{4}$ (Fig. S4 and Table S1†). The Modoping was additionally confirmed by the Raman and XPS spectra. In Fig. 2(b), the Raman spectrum of Mo-doped $\mathrm{BiVO}_{4}$ displayed identical peaks at $325 \mathrm{~cm}^{-1}$ and $368 \mathrm{~cm}^{-1}$, corresponding to the asymmetric and symmetric bending modes $\left(\delta_{\mathrm{as}}\right.$ and $\delta_{\mathrm{s}}$ ) of the $\mathrm{VO}_{4}{ }^{3-}$ tetrahedra, respectively. ${ }^{55}$ And the peaks at $711 \mathrm{~cm}^{-1}$ and $826 \mathrm{~cm}^{-1}$ are assigned to the symmetric and antisymmetric stretching modes $\left(v_{\text {as }}\right.$ and $v_{\mathrm{s}}$ ) of $\mathrm{V}-\mathrm{O}$ vibration, respectively. ${ }^{21,55}$ Both the XRD pattern and Raman spectra revealed that a pure Mo-doped $\mathrm{BiVO}_{4}$ phase was obtained, with no detectable impurities from the other structure or bismuth molybdenites.

The surface oxidation state of 2-Mo- $-\mathrm{BiVO}_{4}$ was characterized by the XPS spectra (in Fig. 2(c)). The peaks at 158.9 and $164.2 \mathrm{eV}$ correspond to the $\mathrm{Bi}_{4 / 2}$ and $\mathrm{Bi}_{7 / 2} \mathrm{f}_{5 / 2}$ electrons of $\mathrm{Bi}^{3+} \cdot{ }^{21}$ The peaks at 232.1 and $235.25 \mathrm{eV}$ are assigned to the $\mathrm{Mo3d}_{5 / 2}$ and $\mathrm{Mo3d}_{3 / 2}$ electrons of $\mathrm{Mo}^{6+}{ }^{56}$ The peaks at 516.53 and $524.02 \mathrm{eV}$ correspond to $\mathrm{V} 2 \mathrm{p}_{3 / 2}$ and $\mathrm{V} 2 \mathrm{p}_{1 / 2}$ electrons of $\mathrm{V}^{5+} .^{21}$ The calculated surface element ratios are 100/5.6/48.9 for $\mathrm{Bi} / \mathrm{Mo} / \mathrm{V}$, indicating a surface deficiency of $\mathrm{V}$ and Mo due to the soaping treatment in alkaline solutions. This is in good agreement with other literature reports. ${ }^{21,57}$ We also used UV-vis absorption (Fig. 2(d)) to investigate the optical properties, where the band edge absorption was close to $510 \mathrm{~nm}$ and the indirect bandgap was $\sim 2.48 \mathrm{eV}$ as determined by the Tauc plot. From the SEM image in Fig. 2(e), 2-Mo-BiVO ${ }_{4}$ exhibited a planar morphology, with particle sizes ranging between 200 and $400 \mathrm{~nm}$. From the inset cross-section image, the film showed a rough surface and the thickness was $c a .130 \mathrm{~nm}$. Next, the elements of the film were analysed through EDS (Fig. 2(f)), showing the evidence of Mo, V and Bi from the film with molar ratios of 100/4.3/111 for $\mathrm{Bi} / \mathrm{Mo} / \mathrm{V}$. The values of the bulk film are higher than those obtained by the XPS surface analysis, presumably due to the larger detect depth through EDS than that through XPS. Thus, the Modoped $\mathrm{BiVO}_{4}$ are well prepared with good quality.

With the well-prepared Fe-doped NiO OER catalyst and Modoped $\mathrm{BiVO}_{4}$ semiconductor film, we next studied charge separation, and recombination kinetics on the semiconductor/ catalyst interface by transient surface photovoltage spectroscopy (TSPV). Although TSPV has been used for the studies of charge separation in a qualitative fashion, the detailed charge kinetics has rarely been examined in a quantitative manner. The deficiency was partially corrected by our recent study on the $\mathrm{Cu}$ doped $\mathrm{CH}_{3} \mathrm{NH}_{2} \mathrm{PbI}_{3}$ perovskite film (p-type) with the ITO substrate, where we applied a first-order serial reaction system for the studies of charge separation at the perovskite/air interface. ${ }^{46}$ Briefly, let us consider a n-type semiconductor as an

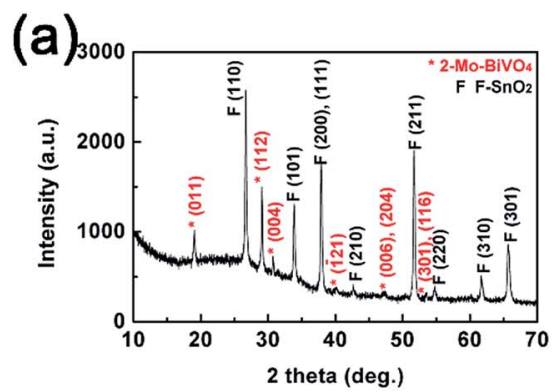

(d)

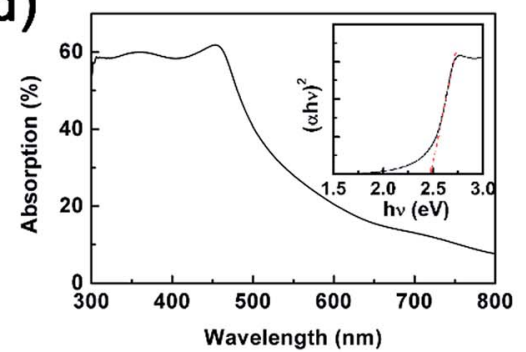

(b)

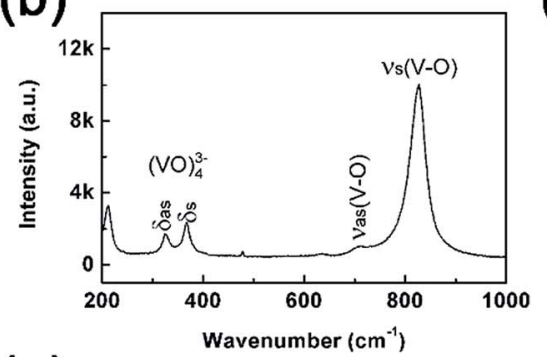

(e)

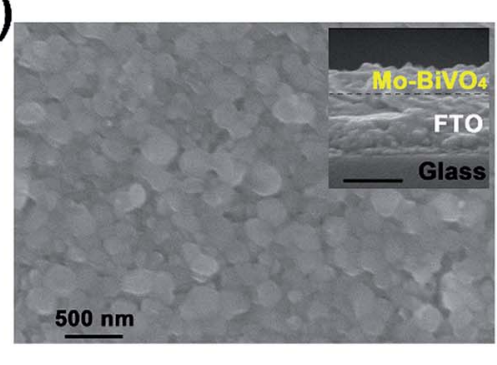

(c)

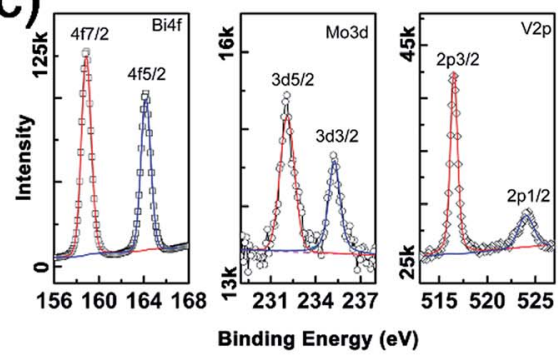

(f)

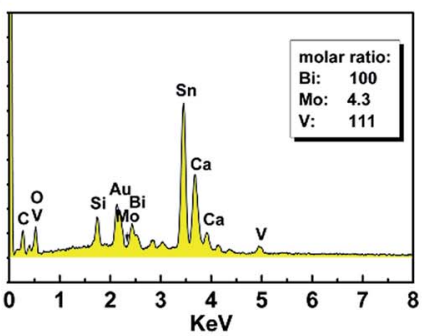

Fig. 2 Structure, spectroscopy, morphology and EDS of the 2-Mo-BiVO 4 film: (a) XRD pattern of the film on the FTO substrate, where peaks marked with red stars are from Mo-doped $\mathrm{BiVO}_{4}$ and marked with a "F" are from FTO; (b) Raman spectrum excited with the 520 nm laser, the peak at $211 \mathrm{~cm}^{-1}$ was attributed to the external mode of lattice vibration; (c) XPS spectra of Bi4f, Mo3d and V2p of the film; (d) UV-vis absorption spectrum; (e) top view and cross-section (inset) image of the film; (f) EDS spectrum of the film. 
example. Upon excitation by a laser pulse with nanosecond temporal resolution (Fig. 3(a)), the electron-hole pairs in the conduction and valence bands will be separated to the semiconductor/air interface due to the internal electric field in the Schottky-type junction, which is regarded as the charge separation process. In the absence of an external circuit, ultimately the separated charges will be consumed through a recombination process. The charge separation/recombination processes (Fig. 3(b)) may be expressed as consecutive equations: ${ }^{46}$

$$
Q_{\text {exc }} \stackrel{k_{\text {sep }}}{\longrightarrow} Q_{\text {sep }} \stackrel{k_{\text {rec }}}{\longrightarrow} Q_{\text {rec }}
$$

Since the charge separation (including the diffusion and drift) is sensitive to the initial excited charge pair densities, a first-order charge separation may be applied to describe the separation process (rate constant: $k_{\text {sep }}$ ). Because the majority charge (electron in n-type semiconductor) density is much higher than the minority charge (hole) density, the recombination is expected to obey a quasi first-order rate law relative to the hole concentration (rate constant: $k_{\text {rec }}$ ). According to the serial first-order reactions theory in physical chemistry, ${ }^{58}$ the intermediate density (accumulated charge) will display a maximum level at the time of $t_{\max }$ (assuming $k_{\text {sep }} \neq k_{\text {rec }}$, other boundary conditions and theoretical calculations can be found in the ESI $\dagger$ ):

$$
t_{\mathrm{max}}=\frac{\ln k_{\mathrm{sep}}-\ln k_{\mathrm{rec}}}{k_{\mathrm{sep}}-k_{\mathrm{rec}}}
$$

Where the transient accumulated charge $\left(Q_{\text {sep }}\right)$ versus the time can be expressed as follows (assuming $k_{\text {sep }} \neq k_{\text {rec }}$ ): ${ }^{46}$

$$
Q_{\text {sep }}=V C=\frac{k_{\text {sep }} Q_{\text {exc }, 0}}{\left(k_{\text {rec }}-k_{\text {sep }}\right)}\left(\mathrm{e}^{-k_{\text {sep } t}}-\mathrm{e}^{-k_{\text {rec }} t}\right)
$$

Where $V$ corresponds to the measured surface photovoltage, $C$ represents the capacity of the assembled TSPV detector (in Fig. 3(a)), and $Q_{\text {exc }, 0}$ is the apparent initial charge pair density.

Based on eqn (6), we could simulate the apparent charge densities of the excited pairs $\left(Q_{\text {exc }}\right)$, separated charge $\left(Q_{\text {sep }}\right)$ and recombined charge $\left(Q_{\text {rec }}\right)$, by varying the three parameters of $k_{\text {sep }}, k_{\text {rec }}$ and $Q_{\text {exc }, 0}$ (Fig. 3(c)-(f)). When an increase in the charge separation kinetics constant (5 times of $k_{\text {sep }}$ in Fig. 3(d)), or a reduction of the charge recombination kinetics constant $(0.2$ times of $k_{\text {rec }}$ in Fig. 3(e)) is introduced, an increase of the maximum accumulated charge $Q_{\text {sep,max }}$ can be seen, together with a negative or positive shift of $t_{\max }$, respectively. Alternatively, when hole storage $Q_{\text {exc, } 0}$ increases, as shown in Fig. 3(f), the $Q_{\text {sep,max }}$ increases, but $t_{\max }$ is unchanged. Therefore, the charge separation or recombination rate constant change can be easily identified through the simulation and/or fitting the TSPV curves.

Next, we obtained the TSPV spectra for doped, undoped $\mathrm{BiVO}_{4}$ films and Fe-NiO modified 2-Mo-BiVO ${ }_{4}$ films in Fig. 3(g)(i), respectively. The experimental data (black) were readily fit by simulated ones (red). The maximum separated charge accumulation displayed sensitivity to doping and surface modifications. It was worth noting that the loading amount of the $\mathrm{NiO}$ on 2-Mo- $\mathrm{BiVO}_{4}$ was proportional to the solid content of the catalyst precursor using EDS analysis (Fig. S5 $†$ ). And the SEM and EDS mapping images of the 2-Mo-BiVO $4 / \mathrm{Fe}-\mathrm{NiO}-12$ were investigated in Fig. S6, $\uparrow$ where all the elements were homogenously distributed in the detected region. Moreover, we found the highest $Q_{\text {sep }}$ on Fe-NiO modified 2-Mo-BiVO ${ }_{4}$ films in Fig. 3(j),
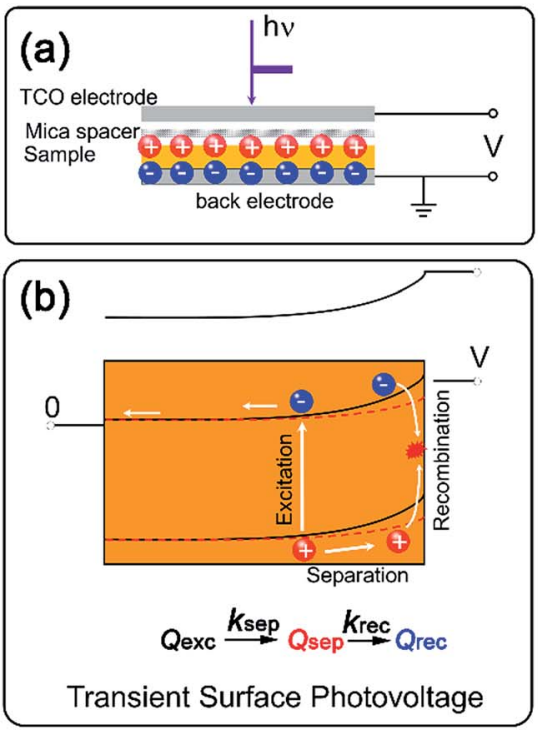

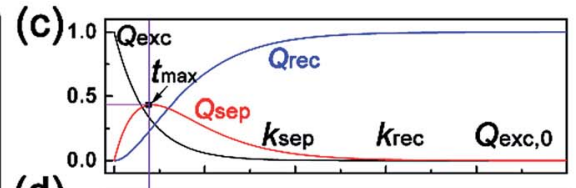

(d)

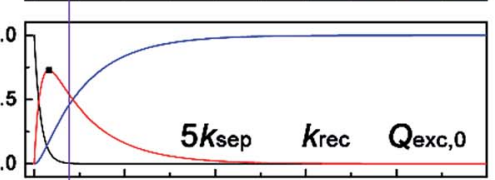

(e)

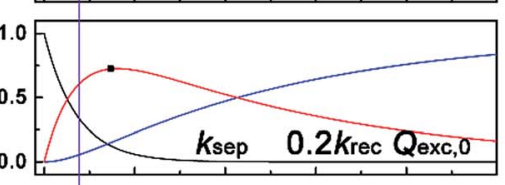

(f)

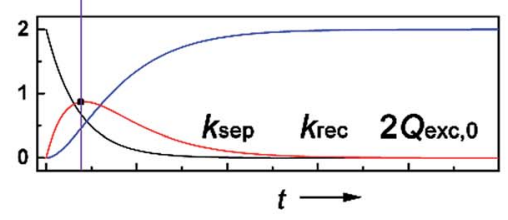

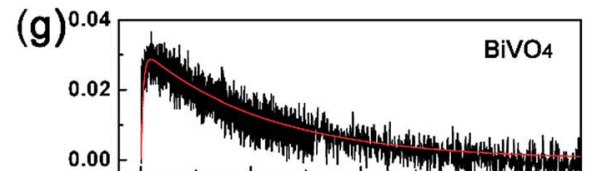

(h)

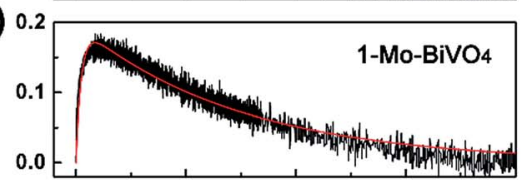

(i)

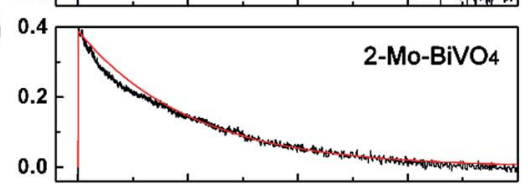

(j)

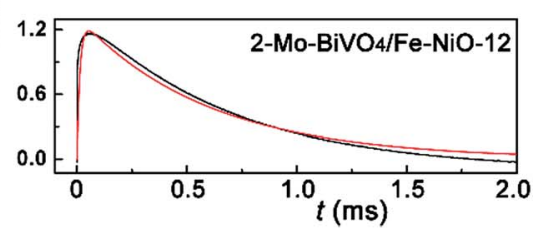

Fig. 3 Transient surface photovoltage of the semiconductor films: (a) capacitor-like surface photovoltage measurement configuration; (b) charge kinetics and band structures with light perturbation (red dashed line corresponds to the light conditions); (c)-(f) are the simulated kinetics for excited, separated and recombined charge densities versus time, according eqn (6). $k_{\text {sep }}, k_{\text {rec }}$ and $Q_{\text {exc,0 }}$ are the rate constants for charge separation, recombination and the apparent "initially" excited charge density, respectively. (g) - (j) are the experimental (black) and simulated (red) TSPV curves for various bismuth vanadate films of $\mathrm{BiVO}_{4}, 1-\mathrm{Mo}-\mathrm{BiVO}_{4}, 2-\mathrm{Mo}-\mathrm{BiVO}_{4}$ and 2-Mo-BiVO $/ \mathrm{Fe}-\mathrm{NiO}-12$, respectively. 
Table 1 Summary of charge separation and recombination kinetics

\begin{tabular}{lllcc}
\hline Bismuth vanadate film & $t_{\max }(\mathrm{s})$ & $k_{\text {sep }}\left(\mathrm{s}^{-1}\right)$ & $k_{\text {rec }}\left(\mathrm{s}^{-1}\right)$ & $Q_{\text {exc,0 }}{ }^{a}($ a.u. $)$ \\
BiVO $_{4}$ & $4.4 \times 10^{-5}$ & $9.2 \times 10^{4}$ & $1.74 \times 10^{3}$ & 0.031 \\
1-Mo-BiVO $_{4}$ & $8.6 \times 10^{-5}$ & $4.1 \times 10^{4}$ & $1.35 \times 10^{3}$ & 0.19 \\
2-Mo-BiVO $_{4}$ & $2.6 \times 10^{-6}$ & $2.8 \times 10^{6}$ & $1.97 \times 10^{3}$ & 0.39 \\
2-Mo-BiVO $_{4} /$ Fe-NiO-12 & $5.3 \times 10^{-5}$ & $7.2 \times 10^{4}$ & $1.69 \times 10^{3}$ & 0.029 \\
\end{tabular}

${ }^{a}$ The relative value of the $Q_{\text {exc,o }}$ were shown here (normalized with $C$ as constant 1).

suggesting a charge storage behavior. The 2-Mo-BiVO ${ }_{4}$ film exhibited the lowest $t_{\max }$, indicating a fast charge separation constant. The parameters were shown quantitatively in Table 1 . We found that undoped $\mathrm{BiVO}_{4}$ showed a $k_{\text {sep }}\left(9.2 \times 10^{4} \mathrm{~s}^{-1}\right)$ higher than 1-Mo-BiVO ${ }_{4}$, while the $2-\mathrm{Mo}-\mathrm{BiVO}_{4}$ had the highest $k_{\text {sep }}$ at $2.8 \times 10^{6} \mathrm{~s}^{-1}$. We have not found a significant separation enhancement at the 2-Mo- $\mathrm{BiVO}_{4} / \mathrm{Fe}-\mathrm{NiO}-12$ interface. For the recombination process, there was no apparent difference in the range of 1.35-1.97 $\times 10^{3} \mathrm{~s}^{-1}$, and no drastic decrease of rate constant was observed. Interestingly, we noticed that the initial charge pairs $\left(Q_{\text {exc }, 0}\right)$ increased from 0.031 on bare undoped $\mathrm{BiVO}_{4}$, to 0.19 on $1-\mathrm{Mo}^{-\mathrm{BiVO}_{4},} 0.39$ on $2-\mathrm{Mo}^{-\mathrm{BiVO}_{4}}$ and 1.3 on the 2-Mo-BiVO $4 / \mathrm{Fe}-\mathrm{NiO}$ samples. For the other amount of Fe$\mathrm{NiO}$ loading on the $2-\mathrm{Mo}^{-\mathrm{BiVO}_{4}}$ films, the TSPV signals were in good agreement with the first-order serial reaction kinetic model (Fig. S7 $\dagger$ ). In addition, we found that a trace amount of Fe-NiO (1.2 ppm dispersion) incorporated into $\mathrm{Mo}-\mathrm{BiVO}_{4}$ could significantly increase the $Q_{\text {exc, } 0}(2.35$ in Table S2 $\dagger)$, but this surface catalyst reduced the charge separation rate constants. On a thick amorphous $\mathrm{NiFeO}_{x}$ layer, we observed two kinetic processes (Fig. S8 and Table S2 $\dagger$ ): one exhibits fast charge recombination $\left(1.64 \times 10^{4} \mathrm{~s}^{-1}\right)$ and large $Q_{\text {exc }, 0}$, and the other one features much slower charge recombination $\left(1.50 \times 10^{2}\right.$ $\mathrm{s}^{-1}$ ) and smaller $Q_{\text {exc,0. }}$. This indicates a difference in the mechanism between the ultra-thin crystalline Fe-doped NiO nanosheets and amorphous thick $\mathrm{NiFeO}_{x}$ layer. It is worth noting that the consecutive-reaction hypothesis is based on the following assumptions, including high excitation rate and efficiency ( $\sim 100 \%)$, fast bulk recombination rate and long lifetime (ns- $\mu \mathrm{s}$ ) of separated charges. Additionally, for all the TSPV measurements, we used the same laser pulse power $(7 \mu \mathrm{J}$ per pulse), therefore the theoretical $Q_{\text {exc,0 }}$ should be at the same level. It is noted that the calculated initial charge density $\left(Q_{\text {exc, } 0}\right)$ is an apparent value and should be treated as such; it may be compared to the values obtained by transient absorption methods only in a qualitative fashion. ${ }^{34,44}$ Moreover, the peak height of the separated charge $\left(Q_{\text {sep,max }}\right)$ on the Fe-doped NiO modified 2-Mo- $\mathrm{BiVO}_{4}$ film displayed 3 times storage as high as that of the bare one (in Table 1). A higher charge separation rate constant could be observed on thinner Fe-NiO application (1.2 or 0.12 samples in Table S2 $\dagger$ ), which also corresponded to higher accumulated charge densities. Therefore, the increased $Q_{\text {sep,max }}$ could be attributed to the "charge storage" effect at the interface.

To better understand the reason of these charge separation kinetics, we used the Kelvin probe force microscope (KPFM) to investigate the surface potential under dark conditions and the photoconductivity on bare and Fe-NiO-12 modified 2-Mo-BiVO films under ambient conditions. In Fig. 4(a), the height image of the bare 2-Mo-BiVO 4 film was shown, with the particle sizes ranging between 150 and $370 \mathrm{~nm}$, consistent with that in the SEM image of Fig. 2(e). When the Fe-NiO-12 was incorporated on the bismuth vanadate surface (Fig. 4(b)), similar particles could be observed with a root-mean-square (RMS) surface roughness factor $R_{\mathrm{q}}$ slightly increased from $19.2 \mathrm{~nm}$ to $20.7 \mathrm{~nm}$. By using an Au film (work function of $5.1 \mathrm{eV}$ ) as the standard, the surface potential of the Mo-doped $\mathrm{BiVO}_{4}$ films were measured between $4.6 \mathrm{~V}$ and $5.2 \mathrm{~V} v$ s. vacuum (corresponding to a $0.1 \mathrm{~V}$ to $0.7 \mathrm{~V} v s$. NHE). The average surface potential was measured as $4.93 \pm 0.09 \mathrm{~V}(0.43 \mathrm{~V} v s$. NHE), which is slightly higher than the reported conduction band minimum $(0.3 \mathrm{~V}){ }^{25}$
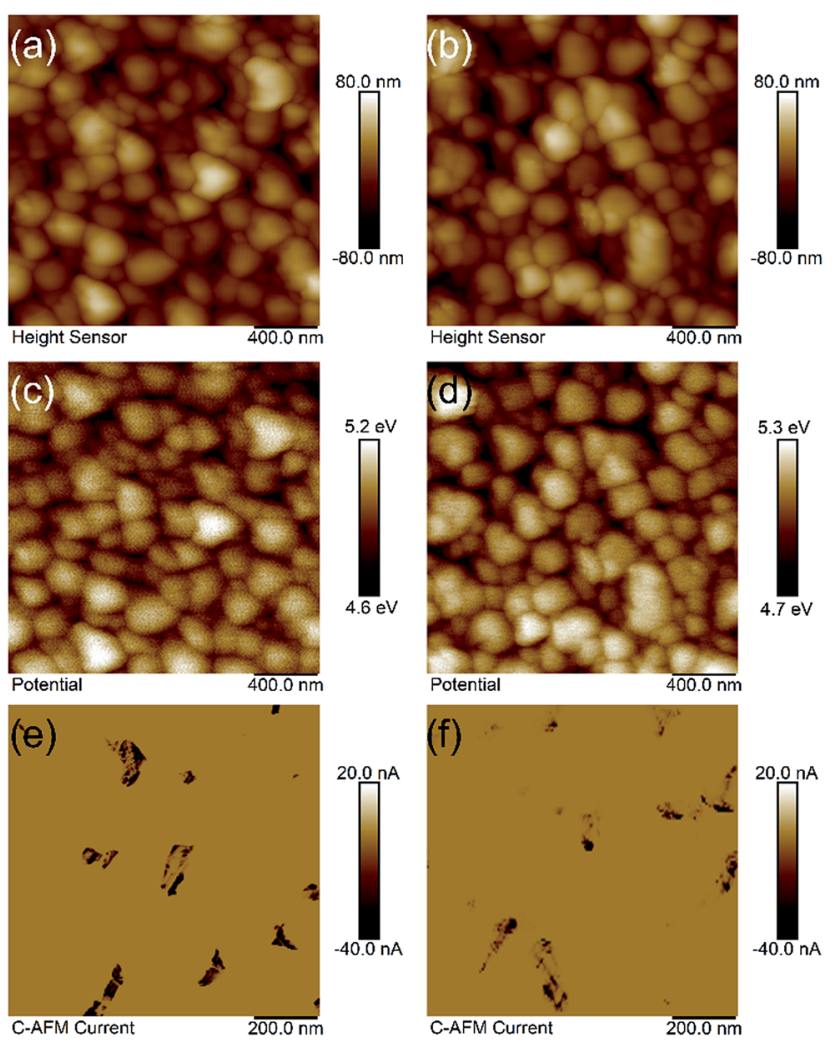

Fig. 4 (a), (c) and (e) are the height image, KPFM surface potential topology and photoconductive-AFM of the 2-Mo-BiVO films; (b), (d) and (f) are the height image, KPFM surface potential topology and photoconductive AFM of the $2-\mathrm{Mo}-\mathrm{BiVO}_{4}$ coated with the Fe-doped $\mathrm{NiO}$ catalyst. The surface potential was calibrated with an Au film (work function at $5.1 \pm 0.02 \mathrm{eV}$ ). The negative photocurrent in C-AFM corresponds to a positive charge flowing to the probe. 
When Fe-NiO was applied onto the surface, the potential (5.03 \pm $0.09 \mathrm{~V})$ ranged between $4.7 \mathrm{~V}$ and $5.3 \mathrm{~V}$ vs. vacuum $(0.53 \mathrm{~V} v s$. NHE). This suggests that the surface potential (or work function) of the films are almost the same, due to the extremely low amount of Fe-NiO. Next, the Mott-Schottky method was applied in an electrochemical setting, and 2-Mo-BiVO 4 showed a flat band potential of $0.20 \mathrm{~V}$ vs. RHE (Fig. S9†). The apparent discrepancy between the Mott-Schottky and Kelvin methods is probably due to the differences in the surface adsorbed species in an electrolyte and in air. It is surprising that the MottSchottky slope of the modified sample is higher than that of the bare one. This may be due to the reduced contribution from surface state capacitance. The $V_{\mathrm{FB}}$ of Fe-NiO modified 2-Mo$\mathrm{BiVO}_{4}$ exhibits a negligible shift. For the Fe-doped NiO nanosheets, a negative slope and $V_{\mathrm{FB}}$ at $1.41 \mathrm{~V} v s$. RHE was obtained (Fig. S10 $\dagger$ ), indicating that the Fe-NiO catalyst features holes as the majority carriers. A possible $\mathrm{p}-\mathrm{n}$ heterojunction between $\mathrm{BiVO}_{4}$ and $\mathrm{Fe}-\mathrm{NiO}$ would facilitate charge separation at the semiconductor|electrocatalyst interface. We also investigated the electronic conductivity of bare and Fe-NiO-12 modified films, with the back illumination from the FTO side. In Fig. 4(e), the photoconductivity of bare 2-Mo- $\mathrm{BiVO}_{4}$ showed random dark domains ( 0 to $-40 \mathrm{nA})$. The average areal photocurrent density was estimated to be $-1.19 \mathrm{nA}$, which was 20 times higher than the dark current $(-0.060 \mathrm{nA})$. After Fe-doped $\mathrm{NiO}$ was deposited on the 2-Mo-BiVO ${ }_{4}$ surface, the photocurrent density slightly decreased to $-0.69 \mathrm{nA}$, indicating that the Fe-NiO layer is less conductive than 2-Mo- $\mathrm{BiVO}_{4}$.

Next, we used photoelectrochemical water splitting to test our understanding that the Fe-NiO nanosheets served as charge reservoirs in the combined system. Different from many other $\mathrm{BiVO}_{4}$ studies which were carried out in phosphate or sulfate solutions, we chose an alkaline solution as the electrolyte because it is widely used in tandem configurations. ${ }^{59}$ In Fig. 5(a), we compared the photocurrent polarization curves of the undoped $\mathrm{BiVO}_{4}$, doped 1-Mo- $\mathrm{BiVO}_{4}$ and 2-Mo-BiVO ${ }_{4}$ films. It (a)
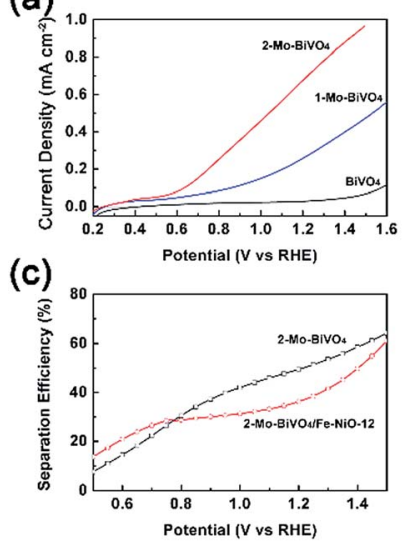

(b)

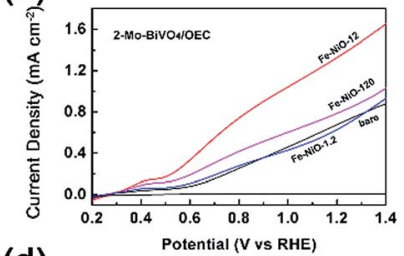

(d)

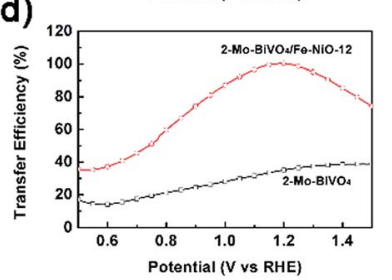

Fig. 5 Photocurrent-potential curves for the $\mathrm{BiVO}_{4}, 1-\mathrm{Mo}-\mathrm{BiVO}_{4}$ and 2-Mo-BiVO 4 photoanodes in (a), various $\mathrm{Fe}-\mathrm{NiO}$ ultrathin nanosheets on the 2-Mo-BiVO 4 photoanodes in (b), respectively. The electrolyte was $1 \mathrm{M} \mathrm{NaOH}$ and the scanning rate was $20 \mathrm{mV} \mathrm{s}^{-1}$. (c) Charge separation efficiency and (d) charge transfer efficiency of the bare and $\mathrm{Fe}-\mathrm{NiO}$ modified 2-Mo-BiVO 4 photoanodes, respectively. was found that the bare $\mathrm{BiVO}_{4}$ sample exhibited a poor water oxidation activity $\left(<0.12 \mathrm{~mA} \mathrm{~cm}^{-2}\right.$ with a positive onset potential at $0.55 \mathrm{~V} v s$. RHE@0.01 $\mathrm{mA} \mathrm{cm}^{-2}$ ). When the Mo dopants were introduced, the photocurrent of $1-\mathrm{Mo}^{-} \mathrm{BiVO}_{4}$ was significantly increased to $c a .0 .40 \mathrm{~mA} \mathrm{~cm}{ }^{-2}$ at $1.4 \mathrm{~V}$, and the onset potential was negatively shifted to $0.27 \mathrm{~V}$. For the $2-\mathrm{Mo}-\mathrm{BiVO}_{4}$ sample, the photocurrent further increased to $0.88 \mathrm{~mA} \mathrm{~cm}^{-2}$ at $1.4 \mathrm{~V}$ and the onset potential remained at $0.27 \mathrm{~V}$. The performance of bare and Mo-doped $\mathrm{BiVO}_{4}$ measured in alkaline solution is among the best of all the reports (Table $\mathrm{S} 3 \dagger) .{ }^{31}$ Moreover, the photoelectrochemical stability of the Mo-doped $\mathrm{BiVO}_{4}$ photoelectrode increased conspicuously with Fe-doped NiO (Fig. S11†), which may be further improved by suitable conformal ALD coating. ${ }^{60}$ Based on this, we further discussed charge separation and transfer in PEC configuration. The trend of the $J-V$ performance on doped and undoped samples is consistent with the TSPV data: 2-Mo-BiVO ${ }_{4}$ exhibited better charge separation and larger charge accumulation and, hence, better PEC performance. Next, in Fig. 5(b), when 2-Mo-BiVO 4 was chosen as a photoelectrode platform, the ultrathin Fe-doped $\mathrm{NiO}$ nanosheets were uniformly dispersed with prolonged ultrasonic treatment and applied onto the bismuth vanadate films. Even with a precursor at $1.2 \mathrm{ppm}$ (which is very low), the photocurrent already increased from $0.15 \mathrm{~mA} \mathrm{~cm}{ }^{-2}$ to $0.18 \mathrm{~mA} \mathrm{~cm}^{-2}(0.7 \mathrm{~V})$ in the range of $0.5-0.8 \mathrm{~V}$ vs. RHE. When the catalyst precursor concentration was increased to $12 \mathrm{ppm}$, the photocurrent increased dramatically to $0.55 \mathrm{~mA} \mathrm{~cm} \mathrm{~cm}^{-2}$ at $0.7 \mathrm{~V}$ and $1.65 \mathrm{~mA} \mathrm{~cm}^{-2}$ at $1.4 \mathrm{~V}$. The loading amount of Fe-NiO on Mo$\mathrm{BiVO}_{4}$ was $0.11-0.12 \mu \mathrm{g} \mathrm{cm}{ }^{-2}$ with the $\mathrm{Fe} / \mathrm{Ni}$ molar ratio at $0.266 / 0.734$, by re-dissolving in dilute $\mathrm{HNO}_{3}$ and analyzed by ICP-MS. Further increase of the precursor concentrations to 120 ppm led to the decrease of the photocurrent to $1.03 \mathrm{~mA} \mathrm{~cm}^{-2}$ at $1.4 \mathrm{~V}$. This is possibly due to the increased charge transfer resistance of the less electronically conductive Fe-NiO by the C-AFM measurements, or by the increased charge transfer resistance at the interface. ${ }^{40}$ Another reason would be increased recombination of the thicker catalyst layers. Although the maximum of the accumulated charge $Q_{\text {sep, max }}$ on $\mathrm{Mo}^{-\mathrm{BiVO}_{4}} / \mathrm{Fe}$ $\mathrm{NiO}$ was higher with the Fe-NiO-0.12 or Fe-NiO-1.2 catalyst (in Fig. S7 and Table S2 $\dagger$ ) than that sample with the Fe-NiO-12 catalyst, extremely thin Fe-NiO-0.12 did not show obvious improvement in the $J-V$ measurements, suggesting that not only the charge storage but also the catalytic sites contributed to the water oxidation reaction. On the other hand, this improvement was also not due to the surface passivation effect. Therefore, when the Fe-NiO modification is used, charge storage, fast kinetics and small transfer impedance need to be balanced consequently.

We then applied charge separation and transfer efficiencies ( $\eta_{\text {sep }}$ and $\eta_{\text {transf }}$ ) in the electrolyte to verify this speculation. We investigated bare and Fe-NiO-12 modified 2-Mo-BiVO ${ }_{4}$ sample in the presence of hydrogen peroxide $\left(\mathrm{H}_{2} \mathrm{O}_{2}\right.$ in $\left.1 \mathrm{M} \mathrm{NaOH}\right)$ as a hole scavenger. By comparing the $J-V$ curves $\left(J_{\mathrm{H}_{2} \mathrm{O}_{2}}\right)$ in $\mathrm{H}_{2} \mathrm{O}_{2}$ (Fig. S12 $\dagger$ ) with the theoretical photocurrent $\left(J_{\text {abs }}\right)$ by light absorption and $100 \%$ IPCE, we estimated the charge separation efficiency $\left(\eta_{\text {sep }}=J_{\mathrm{H}_{2} \mathrm{O}_{2}} / J_{\text {abs }}\right)$ at the semiconductor|electrolyte interface w/o Fe-NiO catalyst in Fig. 5(c). In the range of 
0.5-0.77 V, the charge separation efficiency on $2-\mathrm{Mo}^{-\mathrm{BiVO}_{4}} / \mathrm{Fe}-$ $\mathrm{NiO}-12$ is higher than on bare 2-Mo- $-\mathrm{BiVO}_{4}$. While in the range of $0.77-1.5 \mathrm{~V}$, the charge separation on modified $\mathrm{Mo}^{-\mathrm{BiVO}_{4}}$ one is lower than on the bare one. This suggests that better charge separation is expected on 2 - $\mathrm{Mo}-\mathrm{BiVO}_{4} / \mathrm{Fe}-\mathrm{NiO}-12$ under the lower band bending conditions $(<0.8 \mathrm{~V})$ or slower surface redox reaction rates. The efficiencies of charge transfer to surface water molecules can be evaluated through $\eta_{\text {transf }}=J_{\mathrm{OER}} / J_{\mathrm{H}_{2} \mathrm{O}_{2}}$, assuming that the faradaic efficiencies for water oxidation and $\mathrm{H}_{2} \mathrm{O}_{2}$ oxidation are the same. Fig. 5(d) shows a higher charge transfer efficiency for 2-Mo-BiVO 4 with the Fe-NiO-12 catalyst than that without. For the bare 2-Mo-BiVO ${ }_{4}$ sample, the transfer efficiency slightly increased from 13 to $39 \%(0.5 \mathrm{~V}$ to $1.4 \mathrm{~V})$, suggesting over two thirds of the surface accumulated charges may be consumed by the recombination due to the slow water oxidation kinetics. With ultrathin Fe-NiO nanosheets modification, the charge transfer efficiency significantly improved to close to $99 \%(\sim 1.2 \mathrm{~V})$. This suggested that the higher applied bias $(>0.8 \mathrm{~V})$ contributed more to the surface charge transfer at the Fe-NiO nanosheets-modified $\mathrm{Mo}^{-\mathrm{BiVO}_{4}}$ photoanode rather than the charge separation at the $\mathrm{Mo}-\mathrm{BiVO}_{4}$ photoanode. The relationship between charge separation and transfer under open circuit and PEC conditions is highly complex. Generally speaking, further increases of charge separation and transfer are of great importance to the PEC performance. And the increased transfer efficiency possibly benefits from the charge storage effect at the semiconductor|electrocatalyst interface.

As we have discussed above, through the TSPV, the Fe-doped $\mathrm{NiO}$ ultrathin nanosheet electrocatalyst on the Mo-doped $\mathrm{BiVO}_{4}$ surface displayed a charge storage effect for a better charge separation. Conclusion was obtained by simulations of the kinetics under ambient air conditions without the electrolyte. To further confirm this speculation, we have analysed bare and Fe-NiO-12 modified 2-Mo-BiVO 4 photoelectrodes in a $1 \mathrm{M} \mathrm{NaOH}$ electrolyte by electrochemical impedance spectroscopy (EIS) at $1.5 \mathrm{~V} v s$. RHE and cyclic voltammetry (CV) between 1.1 and $1.6 \mathrm{~V}$ (vs. RHE). In Fig. 6(a) and (c), a typical Nyquist plot of bare 2-Mo$\mathrm{BiVO}_{4}$ were shown, where the capacitance $\left(C_{\mathrm{SS}}\right)$ and resistance $\left(R_{\mathrm{SS}}\right)$ of the surface state were calculated to be $6.42 \times 10^{-6} \mathrm{~F}$ $\mathrm{cm}^{-2}$ and $19.39 \Omega \mathrm{cm}^{2}$, respectively. When the Fe-NiO electrocatalyst was loaded on the 2-Mo-BiVO 4 surface, in Fig. 6(b), we used the electrocatalyst to substitute the surface state circuit as Bisquert and Hamann have done for the Co-Pi coated $\mathrm{Fe}_{2} \mathrm{O}_{3}$ photoanode. ${ }^{61}$ The obtained capacitance $\left(C_{\text {cat }}\right)$ and resistance $\left(R_{\text {cat }}\right)$ of the Fe-NiO catalyst were $2.56 \times 10^{-5} \mathrm{~F} \mathrm{~cm}^{-2}$ and $3.98 \Omega$ $\mathrm{cm}^{2}$ (Fig. 6(d)), respectively. The significant increase of $C_{\text {cat }}$ and reduced $R_{\text {cat }}$ was understood as a benefit for charge separation and the overall photoelectrochemical performance. Moreover, the $\mathrm{CV}$ curves of the $\mathrm{Fe}-\mathrm{NiO}$ modified 2-Mo- $\mathrm{BiVO}_{4}$ showed an obvious current density in the window of 1.2-1.6 V vs. RHE (in Fig. S13†), further confirming the surface capacitance behaviour of the Fe-doped NiO electrocatalyst.

Combining the kinetic charge separation/transfer results at the solid/air interface and solid/liquid interface, we gained the following understanding on the charge separation and transfer processes. The p-type Fe-NiO nanosheets at the n-type 2-Mo$\mathrm{BiVO}_{4}$ surface form an interface that is more complex than (a)

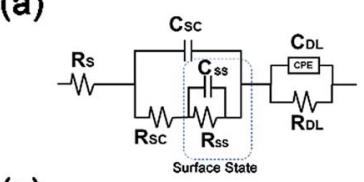

(c)

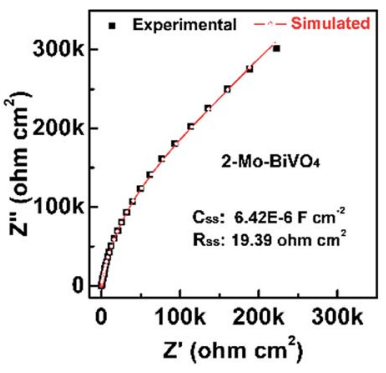

(b)

(d)
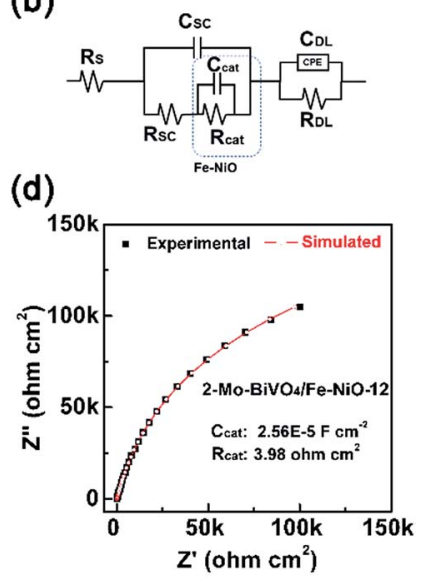

Fig. 6 EIS of the bare and Fe-doped $\mathrm{NiO}$ modified 2-Mo-BiVO photoelectrode measured at $1.5 \mathrm{~V}$ vs. RHE in $1 \mathrm{M} \mathrm{NaOH}$ under dark conditions: (a) and (c) are the electrochemical equivalent circuit and Nyquist plot of the 2-Mo-BiVO ; (b) and (d) are the electrochemical equivalent circuit and Nyquist plot of $2-\mathrm{Mo}-\mathrm{BiVO}_{4} / \mathrm{Fe}-\mathrm{NiO}-12 . R_{\mathrm{S}}, R_{\mathrm{SC}}$, $C_{\mathrm{SC}}, R_{\text {cat }}$ and $C_{\text {cat }}$ corresponded to the serial resistance, space charge region resistance, space charge region capacitance, resistance and capacitance from the catalyst, respectively.

a conventional $\mathrm{p}-\mathrm{n}$ junction as evidenced by the slower charge separation after the Fe-NiO incorporation by TSPV. The increased hole storage at the interface acts as a reservoir possibly due to the $\mathrm{Ni}^{2+} / \mathrm{Ni}^{3+}$ pair in the $\mathrm{Fe}-\mathrm{NiO}$ nanosheets or on the semiconductor side. This surface accumulation of holes induces an internal electric field to impede charge separation, resulting in an apparent slower rate than the bare semiconductor. Moreover, the thicker Fe-NiO nanosheets feature larger resistance/impedance for charge transport. Taken as a whole, we observed relatively low photocurrent on the 2-Mo$\mathrm{BiVO}_{4}$ film modified with Fe-NiO-120 nanosheets. For comparison, we have also checked thick catalyst layers (e.g., $90 \mathrm{~nm}$ ), only to observe increased photocurrents during the first

(a)

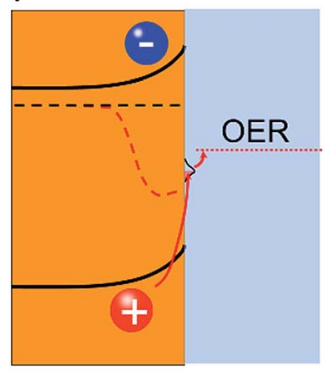

Bare (b)

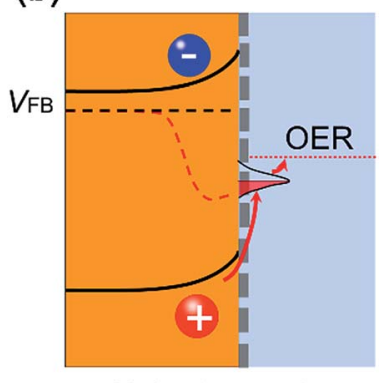

Hole storage layer

Fig. 7 Band structures and charge kinetics on the Mo-doped $\mathrm{BiVO}_{4}$ photoanode with and without ultrathin $\mathrm{Fe}-\mathrm{NiO}$ nanosheet catalysts: (a) less band bending and smaller split of the quasi-Fermi levels of electrons and holes due to the less minority charge accumulation at the surface; (b) larger band bending and split of the quasi-Fermi levels of the electrons and holes due to the significant accumulation of holes at the surface. 
scanning. The performance precipitated drastically during the following scans, due to the slow charge transfer to the electrolyte. Interestingly, the ultrathin Fe-NiO layer is permeable to the alkaline electrolyte and possess the fast charge transfer ability. The performance enhancement as observed in our experiments should be attributed to the ultrathin Fe-doped NiO nanosheets. They not only enable relatively high charge transfer efficiencies but also increase charge storage at the interface. Therefore, we understand this phenomena as the "adaptive" behaviours of the ultrathin nanosheets, ${ }^{9}$ where the photogenerated holes are easily transferred to the redox pairs. By strong contrast, the thick catalyst would form a less "adaptive" junction due to its poor electrical and ionic conductivity, inducing a serious charge recombination and impeding charge transport. ${ }^{6}$ The band structure is schematically illustrated in Fig. 7(a) and (b). The enhanced water oxidation performance is important evidence for the charge storage function of the ultrathin Fe-doped $\mathrm{NiO}$ nanosheets as water oxidation catalysts.

\section{Conclusion}

In this work, we have utilized transient surface photovoltage spectroscopy for the investigation of charge kinetics at the semiconductor|electrocatalyst interface. The Mo-doped bismuth vanadate films have been prepared by the conversion of Bi metal films through a two-step reaction. We used the ionexchange method for the synthesis of ultrathin Fe-doped NiO nanosheets, which could be conveniently applied onto the 2 $\mathrm{Mo}-\mathrm{BiVO}_{4}$ films. On the $2-\mathrm{Mo}-\mathrm{BiVO}_{4} / \mathrm{Fe}-\mathrm{NiO}$ samples, we found that charge separation to the surface led to charge accumulation and eventual annihilation following a firstorder consecutive reaction mechanism. A charge storage $(\sim 3$ times) effect was confirmed on the interface between the ultrathin $\mathrm{Fe}-\mathrm{NiO}$ nanosheet and the $\mathrm{Mo}^{-\mathrm{BiVO}_{4}}$ surface, which significantly enhanced the photoelectrochemical performance. The findings obtained from the planar semiconductor/electrocatalyst system should be easily applied to nanostructured photoelectrodes, which can further increase the photocurrent densities as reported by others. ${ }^{\mathbf{1 3 , 1 4 , 2 1}}$ Both the semiconductor $\mid 2 \mathrm{D}$ electrocatalyst and quantitative transient surface photovoltage analysis may be applied in photoelectrochemistry and other photoelectronic fields for broader impacts.

\section{Conflicts of interest}

There are no conflicts to declare.

\section{Acknowledgements}

The authors greatly thank Prof. Dejun Wang from Jilin University for the transient surface photovoltage setup and measurements. This work in Xuchang University is supported by the National Natural Science Foundation of China (Project No. U1604121, 61504117 and 21673200). D. W. is supported by an Ignite Award at Boston College.

\section{Notes and references}

1 N. S. Lewis, Science, 2016, 351, aad1920.

2 R. C. Armstrong, C. Wolfram, K. P. de Jong, R. Gross, N. S. Lewis, B. Boardman, A. J. Ragauskas, K. EhrhardtMartinez, G. Crabtree and M. V. Ramana, Nat. Energy, 2016, 1, 15020.

3 M. G. Walter, E. L. Warren, J. R. McKone, S. W. Boettcher, Q. Mi, E. A. Santori and N. S. Lewis, Chem. Rev., 2010, 110, 6446-6473.

4 A. Kudo and Y. Miseki, Chem. Soc. Rev., 2009, 38, 253-278.

5 H. Li, Y. Zhou, W. Tu, J. Ye and Z. Zou, Adv. Funct. Mater., 2015, 25, 998-1013.

6 P. Tuan Anh, Y. Ping and G. Galli, Nat. Mater., 2017, 16, 401408.

7 D. R. Gamelin, Nat. Chem., 2012, 4, 965-967.

8 R. Liu, Z. Zheng, J. Spurgeon and X. Yang, Energy Environ. Sci., 2014, 7, 2504-2517.

9 M. R. Nellist, F. A. L. Laskowski, F. D. Lin, T. J. Mills and S. W. Boettcher, Acc. Chem. Res., 2016, 49, 733-740.

10 A. J. Cowan and J. R. Durrant, Chem. Soc. Rev., 2013, 42, 2281-2293.

11 D. Klotz, D. A. Grave and A. Rothschild, Phys. Chem. Chem. Phys., 2017, 19, 20383-20392.

12 Y. Park, K. J. McDonald and K.-S. Choi, Chem. Soc. Rev., 2013, 42, 2321-2337.

13 T. W. Kim and K. S. Choi, Science, 2014, 343, 990-994.

14 Y. Qiu, W. Liu, W. Chen, W. Chen, G. Zhou, P. C. Hsu, R. Zhang, Z. Liang, S. Fan, Y. Zhang and Y. Cui, Sci. Adv., 2016, 2, e1501764.

15 A. Iwase, S. Yoshino, T. Takayama, Y. H. Ng, R. Amal and A. Kudo, J. Am. Chem. Soc., 2016, 138, 10260-10264.

16 S. Gao, B. Gu, X. Jiao, Y. Sun, X. Zu, F. Yang, W. Zhu, C. Wang, Z. Feng, B. Ye and Y. Xie, J. Am. Chem. Soc., 2017, 139, 3438-3445.

17 F. F. Abdi, T. J. Savenije, M. M. May, B. Dam and R. van de Krol, J. Phys. Chem. Lett., 2013, 4, 2752-2757.

18 J. A. Seabold and K. S. Choi, J. Am. Chem. Soc., 2012, 134, 2186.

19 H. L. Tan, R. Amal and Y. H. Ng, J. Mater. Chem. A, 2017, 5, 16498-16521.

20 F. F. Abdi, N. Firet and R. v. d. Krol, ChemCatChem, 2013, 5, 490-496.

21 V. Nair, C. L. Perkins, Q. Lin and M. Law, Energy Environ. Sci., 2016, 9, 1412-1429.

22 J. W. Jang, D. Friedrich, S. Müller, M. Lamers, H. Hempel, S. Lardhi, Z. Cao, M. Harb, L. Cavallo, R. Heller, R. Eichberger, R. v. d. Krol and F. F. Abdi, Adv. Energy Mater., 2017, 7, 1701536.

23 S. Byun, B. Kim, S. Jeon and B. Shin, J. Mater. Chem. A, 2017, 5, 6905-6913.

24 J. Resasco, H. Zhang, N. Kornienko, N. Becknell, H. Lee, J. Guo, A. L. Briseno and P. Yang, ACS Cent. Sci., 2016, 2, 80-88.

25 W. Qiu, Y. Huang, S. Tang, H. Ji and Y. Tong, J. Phys. Chem. C, 2017, 121, 17150-17159. 
26 E. Y. Liu, J. E. Thorne, Y. He and D. Wang, ACS Appl. Mater. Interfaces, 2017, 9, 22083-22087.

27 B. J. Trzesniewski, I. A. Digdaya, T. Nagaki, S. Ravishankar, I. Herraiz-Cardona, D. A. Vermaas, A. Longo, S. Gimenez and W. A. Smith, Energy Environ. Sci., 2017, 10, 1517-1529.

28 S. Wang, P. Chen, J. H. Yun, Y. Hu and L. Wang, Angew. Chem., Int. Ed., 2017, 56, 8500-8504.

29 M. Chhetri, S. Dey and C. N. R. Rao, ACS Energy Lett., 2017, 2, 1062-1069.

30 B. Zhang, L. Wang, Y. Zhang, Y. Ding and Y. Bi, Angew. Chem., Int. Ed., 2018, 57, 2248-2252.

31 M. F. Lichterman, M. R. Shaner, S. G. Handler, B. S. Brunschwig, H. B. Gray, N. S. Lewis and J. M. Spurgeon, J. Phys. Chem. Lett., 2013, 4, 4188-4191.

32 F. F. Abdi and R. van de Krol, J. Phys. Chem. C, 2012, 116, 9398-9404.

33 D. K. Zhong, S. Choi and D. R. Gamelin, J. Am. Chem. Soc., 2011, 133, 18370-18377.

34 Y. Ma, F. Le Formal, A. Kafizas, S. R. Pendlebury and J. R. Durrant, J. Mater. Chem. A, 2015, 3, 20649-20657.

35 C. Zachaeus, F. F. Abdi, L. M. Peter and R. van de Krol, Chem. Sci., 2017, 8, 3712-3719.

36 M. Long, W. Cai and H. Kisch, J. Phys. Chem. C, 2008, 112, 548-554.

37 M. Zhong, T. Hisatomi, Y. Kuang, J. Zhao, M. Liu, A. Iwase, Q. Jia, H. Nishiyama, T. Minegishi, M. Nakabayashi, N. Shibata, R. Niishiro, C. Katayama, H. Shibano, M. Katayama, A. Kudo, T. Yamada and K. Domen, J. Am. Chem. Soc., 2015, 137, 5053-5060.

38 X. Chang, T. Wang, P. Zhang, J. Zhang, A. Li and J. Gong, J. Am. Chem. Soc., 2015, 137, 8356-8359.

39 Y. Liu, Y. Guo, L. T. Schelhas, M. Li and J. W. Ager, J. Phys. Chem. C, 2016, 120, 23449-23457.

40 F. Yu, F. Li, T. Yao, J. Du, Y. Liang, Y. Wang, H. Han and L. Sun, ACS Catal., 2017, 7, 1868-1874.

41 T. Yao, X. An, H. Han, J. Q. Chen and C. Li, Adv. Energy Mater., 2018, 1800210.

42 F. Lin and S. W. Boettcher, Nat. Mater., 2014, 13, 81-86.

43 T. J. Mills, F. Lin and S. W. Boettcher, Phys. Rev. Lett., 2014, 112, 148304.

44 Y. Ma, C. A. Mesa, E. Pastor, A. Kafizas, L. Francàs, F. Le Formal, S. R. Pendlebury and J. R. Durrant, ACS Energy Lett. , 2016, 1, 618-623.
45 L. Kronik and Y. Shapira, Surf. Sci. Rep., 1999, 37, 1-206. 46 K. Lu, Y. Lei, R. Qi, J. Liu, X. Yang, Z. Jia, R. Liu, Y. Xiang and Z. Zheng, J. Mater. Chem. A, 2017, 5, 25211-25219.

47 H. Fan, T. Jiang, H. Li, D. Wang, L. Wang, J. Zhai, D. He, P. Wang and T. Xie, J. Phys. Chem. C, 2012, 116, 24252430 .

48 A. C. Pebley, E. Decolvenaere, T. M. Pollock and M. J. Gordon, Nanoscale, 2017, 9, 15070-15082.

49 S. Li, L. Hou, L. Zhang, L. Chen, Y. Lin, D. Wang and T. Xie, J. Mater. Chem. A, 2015, 3, 17820-17826.

50 Z. Wu, Z. Zou, J. Huang and F. Gao, J. Catal., 2018, 358, 243252.

51 J. A. Dean and N. A. Lange, Lange's Handbook of Chemistry, McGraw-Hill, New York, 1999.

52 M. C. Toroker, D. K. Kanan, N. Alidoust, L. Y. Isseroff, P. Liao and E. A. Carter, Phys. Chem. Chem. Phys., 2011, 13, 1664416654.

53 J. E. Petersen, F. Twagirayezu, L. M. Scolfaro, P. D. Borges and W. J. Geerts, AIP Adv., 2017, 7, 055711.

54 C. C. L. McCrory, S. H. Jung, J. C. Peters and T. F. Jaramillo, J. Am. Chem. Soc., 2013, 135, 16977-16987.

55 V. I. Merupo, S. Velumani, G. Oza, M. Makowska-Janusik and A. Kassiba, Mater. Sci. Semicond. Process., 2015, 31, 618-623. 56 C. V. Cáceres, J. L. G. Fierro, J. Lázaro, A. López Agudo and J. Soria, J. Catal., 1990, 122, 113-125.

57 F. M. Toma, J. K. Cooper, V. Kunzelmann, M. T. McDowell, J. Yu, D. M. Larson, N. J. Borys, C. Abelyan, J. W. Beeman, K. M. Yu, J. Yang, L. Chen, M. R. Shaner, J. Spurgeon, F. A. Houle, K. A. Persson and I. D. Sharp, Nat. Commun., 2016, 7, 12012.

58 P. Atkins and J. d. Paula, Atkins' Physical Chemistry, W. H. Freeman and Company, New York, 8th edn, 2005.

59 E. Verlage, S. Hu, R. Liu, R. J. R. Jones, K. Sun, C. Xiang, N. S. Lewis and H. A. Atwater, Energy Environ. Sci., 2015, 8, 3166-3172.

60 M. T. McDowell, M. F. Lichterman, J. M. Spurgeon, S. Hu, I. D. Sharp, B. S. Brunschwig and N. S. Lewis, J. Phys. Chem. C, 2014, 118, 19618-19624.

61 B. Klahr, S. Gimenez, F. Fabregat-Santiago, J. Bisquert and T. W. Hamann, J. Am. Chem. Soc., 2012, 134, 1669316700. 